\title{
OS CUSTOS PÚBLICOS DA COLETA DE RESÍDUOS SÓLIDOS NA CIDADE DE JUIZ DE FORA
}

Antônio Carlos Sales de Oliveira

Fabiano Rodrigues de Carvalho ${ }^{2}$

Renne José Pereira da Silva ${ }^{3}$

Maury Luna Vieira ${ }^{4}$

Rogerson Antonio Sandes ${ }^{5}$

Lindomar José da Silva Loures ${ }^{6}$

\section{Resumo}

No planejamento urbano, o gerenciamento de resíduos sólidos é uma questão relevante. Este estudo teve como objetivo apresentar um comparativo de gastos da coleta de resíduos sólidos na cidade de Juiz de Fora durante os anos de 2006/2012, utilizando-se de métodos matemáticos e estatísticos. A aprovação da Política Nacional de Resíduos Sólidos no Brasil, provavelmente conduzirá a um esforço para o desenvolvimento de práticas que possam solucionar ou minimizar problemas sociais e ambientais. A falta de estrutura e planejamento para lidar com resíduos sólidos representam um grande problema, talvez o principal passivo ambiental brasileiro. Neste contexto, a educação tem um papel de extrema importância, sendo a família os primeiros a educarem suas crianças, a escola como formadora de opiniões e o Estado em suas competências administrativas. Muito além da simples quantificação dos resíduos sólidos produzidos, da população residente no município e dos custos, o presente trabalho visa compreender melhor a dinâmica entre a produção e os gastos, tendo como subsídio o número de habitantes de Juiz de Fora (MG). Os dados utilizados constam no Anuário Estatístico de Juiz de Fora, ano de 2012. Foi possível notar que a população não apresentou um crescimento notório, contudo os gastos com a destinação final dos resíduos aumentaram de maneira significativa.

Palavras-chave: Lixo. Custos. População Residente.

\section{Introdução}

A gestão de resíduos sólidos é um tema de extrema relevância para o planejamento urbano. Quando ineficiente, pode gerar diversos problemas de cunho social, ambiental e de saúde, onde falta de estrutura e planejamento para lidar com resíduos sólidos representam um grande problema, considerado um dos principais passivos ambientais brasileiros, alvo de muitas críticas num passado recente, devido à emissão de poluentes, poluição dos recursos hídricos e outros impactos. A prática de incineração de resíduos sólidos urbanos apresenta, hoje, tecnologia capaz de atender a rigorosos padrões de operação segura e tende a ser ainda mais comum nos países desenvolvidos.

Segundo o Ministério do Meio Ambiente:

Que institui a Política Nacional de Resíduos Sólidos (PNRS) é bastante atual e contém instrumentos importantes para permitir o avanço necessário ao País no enfrentamento dos principais problemas ambientais, sociais e econômicos decorrentes do manejo inadequado dos resíduos sólidos. Onde um dos principais objetivos é cria metas importantes que irão contribuir para a eliminação dos lixões e institui instrumentos de planejamento nos níveis nacional, estadual, microrregional, intermunicipal e metropolitano e municipal; além de impor que os particulares elaborem seus Planos de Gerenciamento de Resíduos Sólidos.

\footnotetext{
${ }^{1}$ Instituto Federal de Educação, Ciência e Tecnologia do Sul de Minas Gerais, e-mail: antoniospjf@hotmail.com

${ }^{2}$ Instituto Federal de Educação, Ciência e Tecnologia do Sul de Minas Gerais, e-mail: fabianorodriguesdecarvalho@yahoo.com.br

${ }^{3}$ Instituto Federal de Educação, Ciência e Tecnologia do Sul de Minas Gerais, e-mail: jrenne51@yahoo.com.br

${ }^{4}$ Instituto Federal de Educação, Ciência e Tecnologia do Sul de Minas Gerais, e-mail: luna-if@hotmail.com

${ }^{5}$ Instituto Federal de Educação, Ciência e Tecnologia do Sul de Minas Gerais, e-mail: danisandes1@hotmail.com

${ }^{6}$ Instituto Federal de Educação, Ciência e Tecnologia do Sul de Minas Gerais, e-mail: pomar jf@hotmail.com
} 
Para solucionar os sérios problemas da destinação final dos resíduos sólidos da cidade de Juiz de Fora (MG), o Departamento Municipal de Limpeza Urbana - DEMLURB começou a utilizar, no final de 1987, um sítio para destinação dos resíduos sólidos da limpeza urbana, uma área localizada na cidade de Matias Barbosa - MG.

A área em questão, chamada de Sítio Bethânia, não passou por nenhum processo de infraestrutura ou obras de engenharia para receber os resíduos sólidos da cidade, tal espaço era considerado mutável e com possibilidades de inúmeros deslizamentos. Um fato associado à instabilidade do terreno ocorreu no ano de 1994, quando um escorregamento de terra transportou grande quantidade de lixo até as margens de um rio existente no local (VALE, 2007).

O proprietário do imóvel usou o direito de vetar a área em dezembro de 1998, sendo assim, no ano seguinte o município passou a depositar seus resíduos sólidos urbanos em uma área localizada perto da Rodovia BR-040, em uma região denominada Salvaterra, situada a $11 \mathrm{~km}$ do centro da cidade, e que não estava listada entre as áreas pesquisadas como alternativa para a disposição do resíduos do munícipio (MACÊDO, 2011).

Inicialmente, em caráter de emergência, a partir de 1999, parte da região do Salvaterra passou a receber os resíduos em forma de aterro controlado, constituindo o denominado lixão de Salvaterra. Em 20 de agosto de 1999, foi oficializada a implantação do aterro sanitário Salvaterra. Segundo Macêdo (2004, p.95) notou-se claramente "que a decisão foi política e não baseada nos princípios mínimos de respeito às questões ambientais", uma vez que o local contrariava todas as indicações técnicas e legais.

A prefeitura de Juiz de Fora (PJF) anunciou a construção de um aterro sanitário no ano de 2004, o mesmo teria prazo de validade até o ano de 2019. Segundo a PJF seriam usadas as mais valorosas técnicas de segurança e de restauração ambiental com o reflorestamento de toda a área (VALE, 2007). Buscando atender a necessidade da construção de um novo aterro, realizou-se uma análise do munícipio de Juiz de Fora, objetivando localizar uma região tecnicamente viável para a instalação de processos integrados da gestão de resíduos sólidos e cujos custos logísticos fossem minimizados. Tendo em vista a grande produção de resíduos sólidos da população do município em questão, Juiz de Fora tem uma população de aproximadamente 526.706 habitantes e com uma produção de 500 toneladas diárias de lixo. (IBGE, 2010).

Hoje a disposição final dos resíduos no município é feito na Central de Tratamento de Resíduos - CTR Dias Tavares, sua construção se deu em 12 de abril de 2010 com capacidade de receber 500 toneladas de lixo/dia por 25 anos. (DEMLURB, 2013).

A cidade é o espaço social e o local onde o a população dará sequência ao seu processo de socialização, o que nela se faz, se diz e se valoriza representa um exemplo daquilo que a sociedade deseja e aprova. Comportamentos ambientalmente corretos devem ser aprendidos na prática, no cotidiano, contribuindo para a formação de cidadãos responsáveis. Considerando a importância da temática ambiental e a visão integrada do mundo, no tempo e no espaço, a cidade deverá oferecer meios efetivos para que cada cidadão entenda o seu papel na sociedade.

Sabe-se que a questão da produção de resíduos sólidos envolve muitas responsabilidades e constitui um dos problemas mais sérios da atualidade, pois está diretamente associada à qualidade ambiental e à saúde pública. Apesar da complexidade das questões, existem várias alternativas de destinação correta e reaproveitamento dos materiais.

A situação torna-se mais crítica nas cidades de grande porte, a exemplo da cidade de Juiz de Fora (MG), onde a disposição é feita de forma inadequada e a coleta seletiva é ineficiente; o que resulta em problemas como: a poluição do solo, do ar e das águas. A situação atual reflete uma gestão de resíduos sólidos sem preocupação com planejamento e sem nenhuma responsabilidade ambiental (BROLLO, 2001). A forma correta de dispor os resíduos sólidos urbanos é em aterro sanitário, cuja construção, operação e encerramento baseiam-se em critérios de engenharia e normas operacionais específicas. (ARAUJO et al., 2007).

Para Leroy (2006), a introdução de novos produtos na vida moderna, e em quantidades cada vez maiores, fez com que os resíduos familiares passassem a ser uma ameaça ao ambiente, causando danos enormes ao meio ambiente.

Nesse contexto, a educação tem um papel de extrema importância, sendo a família a primeira a educar suas crianças, a escola a atuar como formadora de opiniões e o Estado em suas competências administrativas. Daí a importância dessa rede de articulações: pais, professores e governantes estarem articulados com discursos que levem a uma prática eficiente (FURNIVAL, 2006).

Muito além do estabelecimento de padrões de reciclagem ou limpeza urbana, a intenção com este trabalho é uma conscientização sobre o modo de utilização dos produtos em nosso contexto de vida. De forma mais direta, a discussão central se dará em torno de compreender a dinâmica do custo da coleta de resíduos na 
cidade de Juiz de Fora no período de 2006 a 2012, utilizando-se de métodos matemáticos e estatísticos para compreender a dinâmica desses custos.

\section{Material e métodos}

Foram utilizados como material para a elaboração deste trabalho os dados publicados no Anuário Estatístico de Juiz de Fora de 2012, organizado pelo Centro de Pesquisas Sociais da Universidade Federal de Juiz de Fora (CPS/UFJF, 2012), dados do site do Departamento Municipal de Limpeza Urbana - DEMLURB de Juiz de Fora; pesquisas em periódicos e leis da área ambiental, além de trabalhos de autores como ARAUJO (2007); FURNIVAL (2006); LEROY (2006); MACÊDO (2011); VALE (2007); MAGALHÃES (2008); TEIXEIRAS (2006).

Juiz de Fora localiza-se no interior de Minas Gerais, pertencente à mesorregião da Zona da Mata e microrregião de mesmo nome. No ano de 2010, a população foi estimada em 526.706 habitantes, pelo Instituto Brasileiro de Geografia e Estatística, sendo então o quarto mais populoso de Minas Gerais e o $36^{\circ}$ do Brasil. Ocupa uma área de $1.429,875 \mathrm{~km}^{2}$, sendo que apenas $317,740 \mathrm{~km}^{2}$ estão em perímetro urbano (DEMLURB, 2013).

O presente artigo utilizou como dados primários informações disponibilizados no sítio do Departamento Municipal de Limpeza Urbana (DEMLURB, 2013) da cidade de Juiz de Fora e dados apresentados no Anuário Estatístico 2012, de autoria da Universidade Federal de Juiz de Fora (UFJF) em conjunto com Centro de Pesquisa Social.

Buscou-se, por meio de ferramentas gráficas, elaborar dados comparativos entre os fatores: produção de resíduos sólidos por dia e população residente no município, além de tabelas que demonstram os valores gastos com a gestão de resíduos.

No presente estudo, optou-se por analisar os dados referentes aos valores fixados pelo DEMLURB para serem gastos no período de 2006 a 2012, e também os valores realmente gastos naquele período, ou seja, o custo de execução.

Foi aplicado o teste $t$ de Student, com o auxílio do Microsoft Office Excel 2007, para verificar a ocorrência de variação estatisticamente significativa $(p<0,05)$ entre os valores do custo de execução (DEMLURB, 2013), número de habitantes e a quantidade (toneladas) de resíduos produzidos por dia das matrizes formadas com os dados dos sete anos monitorados (2006 a 2012).

\section{Resultados e discussão}

O enfoque da pesquisa foi dado à quantidade de resíduo sólido produzido (Figura 1), à população residente na cidade de Juiz de Fora (Figura 2) e ao custo operacional da destinação final dos resíduos sólidos (Tabela 1).

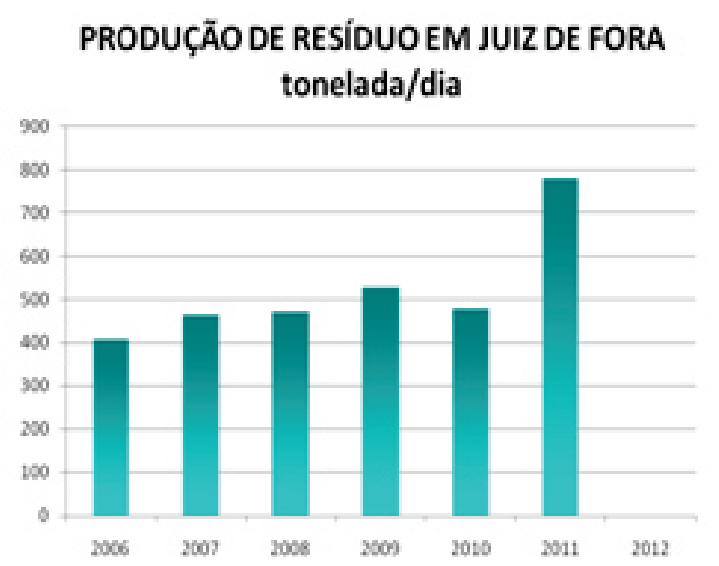

Figura 1- Produção de Resíduo em Juiz de Fora (ton/dia). Fonte: Anuário UFJF/DEMLURB.

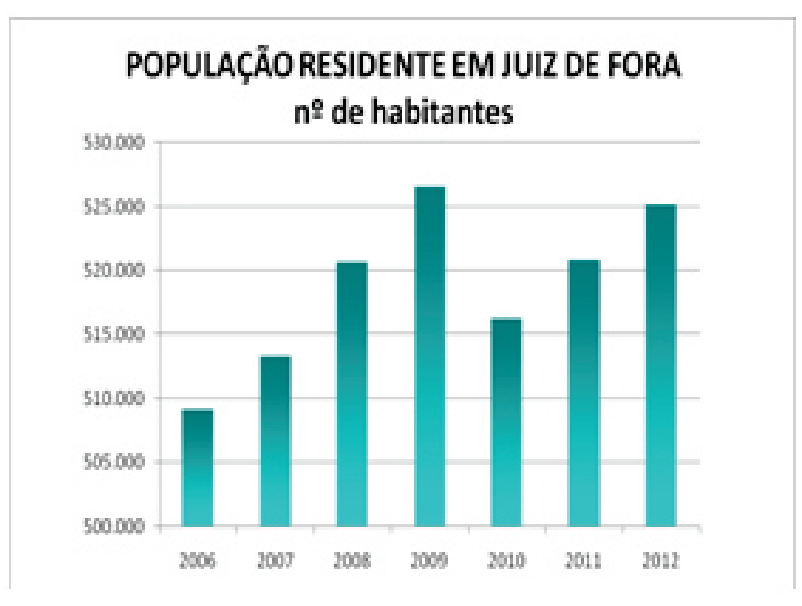

Figura 2 - População Residente em Juiz de Fora.

Fonte: Anuário UFJF/DEMLURB 
Com base na análise da figura 1, pode-se observar que não há uma grande variação na produção de resíduos sólidos na cidade de Juiz de Fora entre os anos de 2006 e 2010; também é possível observar que no ano de 2011 a produção apresenta valores próximos de 800 toneladas/dia, o que configura um aumento notório na quantidade de resíduos. Buscando compreender a situação observada em 2011 de que a Central de Tratamento de Resíduo CTR - Dias Tavares passou a receber resíduos de outros municípios.

Vale destacar que informações disponibilizadas no sítio do DEMLURB apontam que o aterro tem capacidade de receber 500 tonelada/dia, o que possibilitaria uma vida útil de 25 anos, os valores encontrados em 2011 excedem a quantidade diária estipulada, tendo como consequência a redução da vida útil do aterro sanitário e o aumento dos custos em longo prazo. Ressalta-se que a ausência de dados no ano de 2012 (figura 1) deve-se à utilização de dados apresentados no anuário estatístico de tal ano.

Ao observar a figura 2, pode-se concluir que há uma flutuação no número de habitantes residentes em Juiz de Fora no decorrer dos anos. Espera-se que com o crescimento da população também ocorra o aumento da produção de resíduos, fato não observado na prática, uma vez que, no ano de 2009, o aumento do número de habitantes no município não correspondeu ao ano de maior produção de resíduos. A variação quantitativa de habitantes deve-se ao fato de Juiz de Fora ser uma cidade polo, atraindo diversas pessoas para inúmeros fins (saúde, acadêmico, trabalho, dentre outros).

Avaliando-se a ocorrência ou não de variação estatisticamente significativa $(p<0,05)$, com a aplicação do teste t para quantidade de resíduo sólido (tonelada/dia), população residente (habitante) e custo total de operação (Reais), foi possível notar que entre os anos estudados (2006 a 2012), não ocorreu variação estatisticamente significativa, uma vez que os valores foram superiores a 0,05ro. Contudo, vale ressaltar que 0 valor obtido para o teste $t$ ao analisarmos o custo $(p=0,061)$ é o mais próximo do valor limite para se afirmar que ocorreu variação (tabela 3 ). Já o resultado do teste $t$ para resíduo sólido (tabela 1 ) e população (tabela 2) foram $p=0,287$ ro e $p=0,358$ ro, respectivamente.

Tabela 1 - Resultado do teste $t$ e dados estatísticos dos resíduos sólidos.

\begin{tabular}{ccc}
\cline { 1 - 1 } & \multicolumn{3}{c}{$\begin{array}{c}\text { Resíduos } \\
\text { Sólidos } \\
\text { (ton/dia) }\end{array}$} \\
\hline $2006-2007$ & 408,60 & 462,69 \\
$2007-2008$ & 462,69 & 469,67 \\
$2008-2009$ & 469,67 & 530,01 \\
$2009-2010$ & 530,01 & 477,76 \\
$2010-2011$ & 477,76 & 780,07 \\
$2011-2012$ & 780,07 & $*$ \\
\hline Média & 469,74 & 544,04 \\
Variância & 1871,15 & 18112,19 \\
Correlação de Pearson - 0,15 & & \\
Número de observações - 5 & & \\
Grau de Liberdade - 4 & & \\
\cline { 1 - 1 } Hipótese da diferença da & & \\
média = 0 & & \\
P(t<=t) bi-caudal & 0,287 & \\
t crítico bi-caudal & 2,776 & \\
\hline
\end{tabular}

Fonte: Elaboração dos autores 
Tabela 2 - Resultado do teste te dados estatísticos da população residente em Juiz de Fora (MG).

\begin{tabular}{ccc}
\hline Ano & População & \\
\cline { 1 - 2 } $2006-2007$ & 509.125 & 513.348 \\
$2007-2008$ & 513.348 & 520.612 \\
$2008-2009$ & 520.612 & 526.612 \\
$2009-2010$ & 526.612 & 516.247 \\
$2010-2011$ & 516.247 & 520.810 \\
$2011-2012$ & 520.810 & 525.225 \\
\hline Média & $517.792,33$ & $520.475,67$ \\
Variância & $3.8421 .234,67$ & $25.805 .274,67$ \\
Correlação de Pearson - 0,35 & & \\
Número de observações - 6 & & \\
Grau de Liberdade -5 & & \\
\cline { 1 - 1 } Hipótese da diferença da média $=0$ & & \\
P(t<=t) bi-caudal & 0,358 & \\
t crítico bi-caudal & 2,570 & \\
\cline { 1 - 2 } & &
\end{tabular}

Fonte: Elaboração dos autores

Tabela 3 - Resultado do teste $t$ e dados estatísticos referentes ao custo com a gestão dos resíduos sólidos na cidade de Juiz de Fora.

\begin{tabular}{|c|c|c|}
\hline Ano & Custo $(R \$)$ & \\
\hline $2006-2007$ & * & * \\
\hline $2007-2008$ & * & * \\
\hline $2008-2009$ & $30.554 .428,04$ & $30.863 .290,99$ \\
\hline $2009-2010$ & $30.863 .290,99$ & $34.295 .288,43$ \\
\hline $2010-2011$ & $34.295 .288,43$ & $40.462 .219,76$ \\
\hline $2011-2012$ & $40.462 .219,76$ & $45.858 .519,20$ \\
\hline Média & $34.043 .806,81$ & $37.869 .829,6$ \\
\hline Variância & $2,11836 \mathrm{E}+13$ & $4,41362 \mathrm{E}+13$ \\
\hline \multicolumn{3}{|l|}{ Correlação de Pearson - 0,96 } \\
\hline \multicolumn{3}{|l|}{ Número de observações - 4} \\
\hline \multicolumn{3}{|l|}{ Grau de Liberdade - 3} \\
\hline \multicolumn{3}{|l|}{ Hipótese da diferença da média $=0$} \\
\hline $\mathrm{P}(\mathrm{t}<=\mathrm{t})$ bi-caudal & 0,061 & \\
\hline t crítico bi-caudal & 3,182 & \\
\hline
\end{tabular}

Fonte: Elaboração dos autores

Após uma filtragem dos dados do Anuário Estatístico 2012 e das informações de custos, disponibilizadas no endereço eletrônico do DEMLURB, foi elaborada a seguinte tabela (tabela 4): 
Tabela 4 - Dados de custos previstos x execução; e custos por habitantes no município de Juiz de fora.

\begin{tabular}{|c|c|c|c|c|c|c|}
\hline & CUSTO (R\$) & & CUSTO (R\$) & & & \\
\hline Ano & Fixado & Execução & Diferença & $\begin{array}{c}\text { Previsto/ } \\
\text { Habitante }\end{array}$ & $\begin{array}{l}\text { Execução/ } \\
\text { Habitante }\end{array}$ & Diferença \\
\hline 2006 & * & * & * & * & * & * \\
\hline 2007 & * & * & * & * & * & * \\
\hline 2008 & $30.606 .831,87$ & $30.554 .428,04$ & $52.403,83$ & 58,79 & 58,69 & 0,10 \\
\hline 2009 & $30.930 .227,00$ & $30.863 .290,99$ & $66.936,01$ & 58,73 & 58,61 & 0,13 \\
\hline 2010 & $34.960 .383,00$ & $34.295 .288,43$ & $665.094,57$ & 67,72 & 66,43 & 1,29 \\
\hline 2011 & $40.938 .824,00$ & $40.462 .219,76$ & $476.604,24$ & 78,61 & 77,69 & 0,92 \\
\hline 2012 & $44.752 .216,00$ & $45.852 .519,20$ & $-1.100 .303,20$ & 85,21 & 87,30 & $-2,09$ \\
\hline
\end{tabular}

Fonte: DEMLURB, 2013.

Os dados de 2006 e 2007 não constam na tabela 1, os mesmos não estão disponíveis no sítio eletrônico e também não foram fornecidos em tempo hábil pelo Departamento Municipal de Limpeza Urbana, cabe destacar que a solicitação foi realizada com a antecedência devida, mas o referido órgão não atendeu ao pedido.

A tabela 1 sintetiza uma série de informações associadas ao custo de toda a gestão de resíduos sólidos feitas pelo DEMLURB, o custo de execução aumenta a cada ano, com algumas ponderações e interpretações, as quais serão descritas.

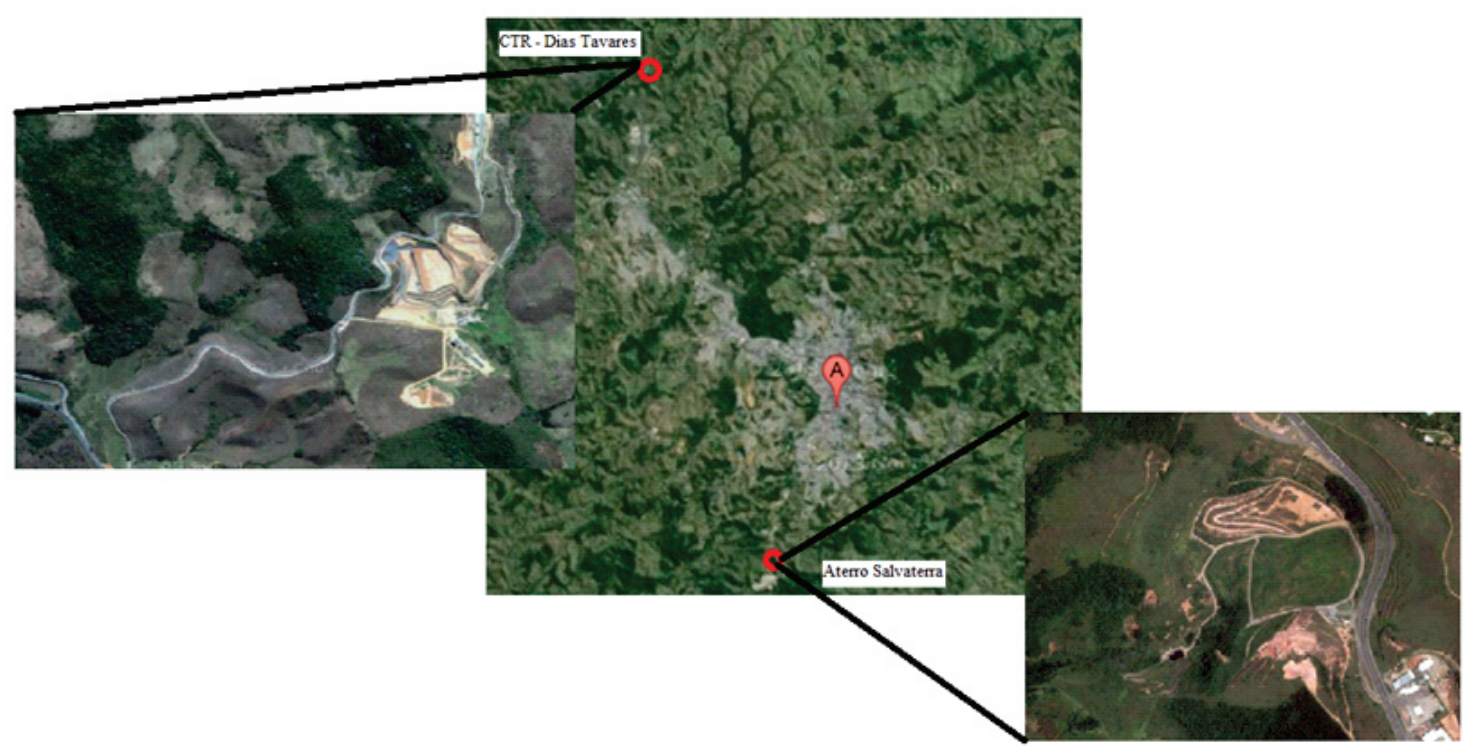

Figura 3 - Mapa de localização do Aterro Salvaterra e da CTR Dias Tavares. Enfoque para o centro gerador de resíduo (letra "A").

Fonte: Google Earth e dados dos autores, 2013.

Os dados que constam de 2008 a 2009 referem-se exclusivamente a toda a logística do setor com disposição final dos resíduos no Aterro Sanitário Salvaterra. Não houve um aumento expressivo nos valores entre os anos em questão. A partir de 2010, ano no qual foi inaugurado o CTR Dias Tavares, houve um aumento 
progressivo dos valores que culminam, no ano de 2012, com cifras de execução superiores às fixadas para 0 período.

Observa-se na figura 1 que os anos de 2008 e 2010 apresentam valores semelhantes de resíduos produzidos, era de se esperar que o custo de execução fosse também próximo, fato que não é observado na prática, conforme pode ser constatado na tabela 1. Uma possível justificativa para a questão é o fato de que em 2010, com o funcionamento da CTR Dias Tavares, houve um aumento da distância entre o centro gerador dos resíduos e a disposição final do mesmo, acarretando maiores custos com o transporte (figura 3), fato esse que também pode ser observado com o aumento da relação custo de execução/habitante, que tem um incremento notório a partir do ano de 2010.

Embora não constem os dados da produção de resíduos do ano de 2012 (figura 1), as cifras disponibilizadas no endereço eletrônico do DEMLURB para o referido ano merecem atenção e investigação mais detalhadas, tendo em vista a diferença do valor fixado e o valor realmente empregado na execução, como pôde ser observado na tabela 1.

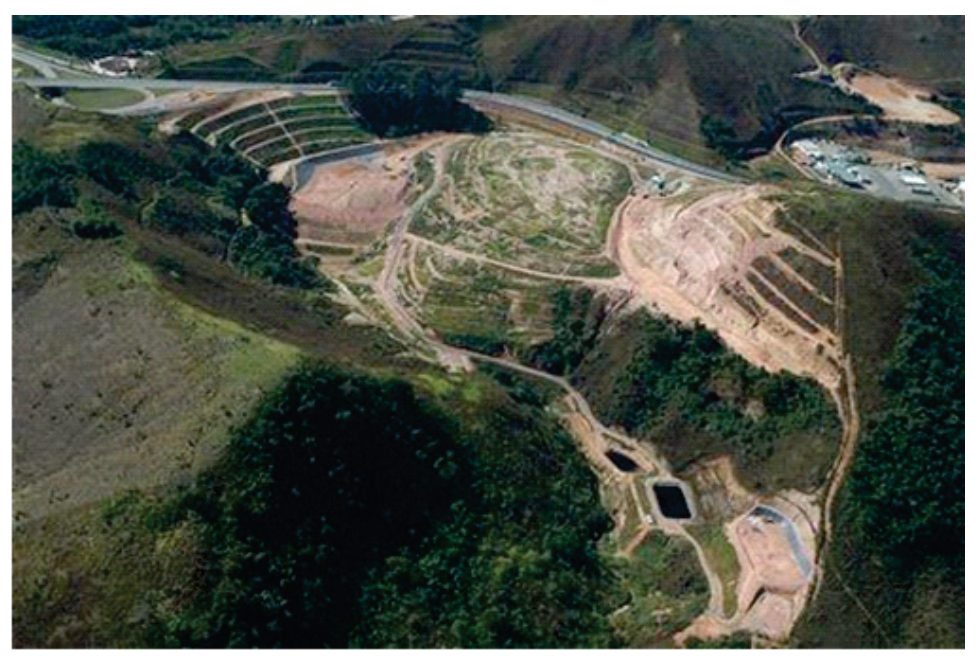

Figura 4: Aterro Antigo Salvaterra.

Fonte: Departamento Municipal de Limpeza Urbana (DEMLURB)

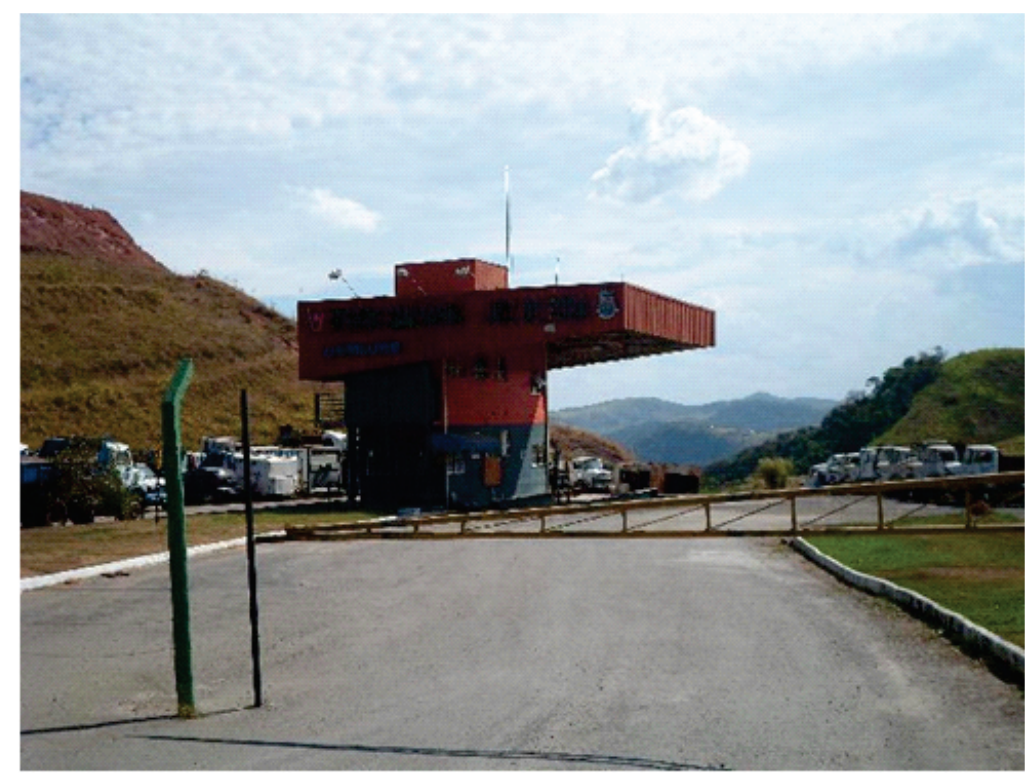

Figura 5: Aterro Sanitário desativado - Salvaterra.

Fonte: Elaboração dos autores, 2013. 
Procurando dar destaque no trabalho, inseriu-se a Figura 4 do Aterro Sanitário Salvaterra que se encontra desativado, no qual se pode notar uma área já com vegetação rasteira, pequenas gramíneas e algumas árvores, além de um curso hídrico nas proximidades das bacias de chorume. Essa região passou por inúmeros deslizamentos até o momento de ser desativada, no ano de 2009. A Figura 5 evidencia a entrada do Aterro Sanitário Salvaterra, desativado e servindo como depósito de equipamentos (caminhões e máquinas) do DEMLURB.

\section{Conclusão}

Após análise dos dados e interpretação de seus resultados foi possível concluir que um evento marcante no histórico da gestão dos resíduos sólidos no município de Juiz de Fora foi a criação da CTR Dias Tavares,em 12 de abril de 2010,que refletiu num aumento dos custos, principalmente por se tratar de uma empresa privada, que atualmente recebe os resíduos e cobra por tonelada.

A maioria das decisões com relação à localização e tempo de utilização dos locais teve motivações políticas, desconsiderando os aspectos ambientais, sociais, econômicos e técnicos para a implantação, operação e alteração dos locais de destinação dos resíduos da cidade de Juiz de Fora.

Outro aspecto que merece destaque é o fato de não ter sido observada nenhuma iniciativa para implantação da gestão integrada dos resíduos, processo que traria grandes benefícios, pois reduziria substancialmente o volume de material destinado ao aterro, gerando matéria prima para as indústrias de reciclagem da cidade e região.

Os resultados demonstram a necessidade de um acompanhamento sistêmico da produção dos resíduos e dos gastos envolvidos na destinação dos mesmos, tendo em vista um aumento gradual nas despesas do Departamento Municipal de Limpeza Urbana, com ênfase no ano de 2012, principalmente por se tratar de uma administração de verbas públicas.

\section{Agradecimentos}

Nosso agradecimento especial aos tutores Thiago Martins da Silva e Márcio de Souza Dias pela orientação durante o desenvolvimento desta pesquisa.

\section{The public costs of solid waste collection in the city of Juiz de Fora}

\section{Abstract}

In the urban planning, the solid waste management is a relevant question. The study aimed to present a comparative expense of solid waste collection in the city of Juiz de Fora during the years 2006/2012, using mathematical and statistical methods. The approval of the National Policy on Solid Waste in Brazil, probably will lead to an effort to develop practices that can solve or minimize social and environmental problems. The lack of structure and planning to deal with solid waste; represent a major problem, perhaps the leading Brazilian environmental liability. In this context, the education has a very important role, being the family the first to educate their children, the school in forming opinion and construction of knowledge and the state in its administrative competences. Far beyond simple quantification of solid waste produced, the population of the municipality and costs, this study aims to better understand the dynamics between production and costs, taking as subsidy the number of inhabitants of Juiz de Fora (MG). The data used are contained in the Statistical Yearbook of Juiz de Fora, 2012. Was possible observed that the population not had a notorious growth, however spending on final disposal of waste increased significantly.

Key words: Trash. Costs. Resident Population. 


\section{Referências Bibliográficas}

ARAUJO, G. H. S.; ALMEIDA, J. R.; GUERRA, A. J. T. Gestão Ambiental de Áreas Degradadas. 2.ed. Rio de Janeiro: Bertrand Brasil, 2007.

BRASIL. Lei n. ${ }^{\circ} 12.305$ de 02 de agosto de 2010. Institui a Política Nacional de Resíduos Sólidos; altera a Lei n 9.605, de 12 de fevereiro de 1998; e dá outras providências. Diário Oficial [da]República Federativa do Brasil, Brasília, DF, n. ${ }^{\circ}$ 147, p. 3, 03 de ago. 2010.

BROLLO, M. J.; SILVA, M. M. Política e Gestão Ambiental em Resíduos Sólidos. CPS - Centro de Pesquisa Sociais / Universidade Federal de Juiz de Fora. Anuário Estatístico de Juiz de Fora, 2012. Disponível em: <http://www.cps.ufjf.br>. Acesso em: 11 ago. 2013.

BROLLO, M.J; SILVA, M.M. Política e Gestão Ambiental em resíduos sólidos. Revisão e Analise sobre a atual situação no Brasil. In: $21^{\circ}$ Congresso Brasileiro de Engenharia Sanitária e Ambiental. Anais... João Pessoa, 2001.

DEMLURB. Histórico Recente da Destinação Final de Resíduos Sólidos em Juiz de Fora - MG. Disponível em: <http://www.demlurb.pjf.mg.gov.br/aterro.php>. Acesso em: 3 abr. 2013.

FURNIVAL, A.C. Dimensões Culturais do Consumo: reflexões para pensar sobre o consumo sustentável. In: CINQUETTI, H. C. S.; LOGAREZZI, A. ( Orgs.). Consumo e Resíduo: fundamentos para o trabalho educativo. São Carlos:EdUFSCar, 2006.pp.59-84.

INSTITUTO BRASILEIRO DE GEOGRAFIA E ESTATÍSTICA (IBGE). Disponível em: <www.ibge.gov.br/catálogos/indicadores> Acesso em: 11 ago. 2013.

Sinopse do Censo Demográfico 2010. Rio de Janeiro, 2011. 1 CD-ROM.

LEROY, J. P.; PACHECO, T. Dilemas de uma Educação em Tempo de Crise. In: LOUREIRO, C. F. B.;Castro, R. S.(Orgs.). Pensamento Complexo, Dialética e educação Ambiental. São Paulo: Cortês, 2006.p.30-71.

MACÊDO, J. A. B. Parâmetros físicos [mensagem pessoal]. Mensagem recebida por <j.macedo@terra.com.br> em 20 set. 2011 a.

MACHADO, P. J. O. (Org.). Diagnóstico Físico-Ambiental da Bacia Hidrográfica do Córrego São Pedro: um exercício acadêmico de Gestão dos Recursos Hídricos. Juiz de Fora: Geographica, 2010.p. ???

MAGALHÃES, P. Aterro Sanitário Provoca Discussões. Acessa.com: mais comunição.S.l.: 4 jul. 2008. Disponível em: <http://www.acessa.com/cidade/meioambiente/aterro_sanitario/>. Acesso em: 05 jul. 2013.

TEIXEIRA, G. P. et al. Considerações sobre a Remediação e Monitoramento Geotécnico e Ambiental do Lixão de Salvaterra - Juiz de Fora / MG. CONGRESSO BRASILEIRO DE ENGENHARIA SANITÁRIA E AMBIENTAL, 24, 2007, Belo Horizonte, 2007. Disponível em: <http://www.thecnna.com/pdf/076.pdf>. Acesso em: 12 abr. 2013.

TEIXEIRA, G. P.; FRANÇA, R. A.; LACERDA, G. B. M. Metodologia de Operação de Aterro Sanitário no Município de Juiz de Fora - MG. SEMINÁRIO NACIONAL DE RESÍDUOS SÓLIDOS. 8. 2006. ABES/MA - Seção Maranhão da Abes. Maranhão, 2006. Disponível em: <http://www.thecnna.com/pdf/aterro.pdf>. Acesso em: 08 abr. 2013. 
VALE, C. S. Custos ambientais, sociais e econômicos da escolha inadequada de local para a disposição final dos resíduos sólidos urbanos: o caso da cidade de Juiz de Fora. 2007. Dissertação de Mestrado - Programa de Pós-Graduação em Ciência Ambiental, Universidade Federal Fluminense, Niterói, 2007.

\section{Histórico}

Submetido em 24/10/2013

Aceito em: 06/05/2014 